\title{
Entrepreneurial motivation and self-employment: evidence from expectancy theory
}

\author{
Virginia Barba-Sánchez ${ }^{1}$ (D) Carlos Atienza-Sahuquillo ${ }^{1}$
}

Published online: 16 March 2017

(C) The Author(s) 2017. This article is published with open access at Springerlink.com

\begin{abstract}
One effect of the economic crisis on the business world has been the drastic reduction in staff and this in turn highlights the need for self-employment and the creation of new companies to establish a solid industrial fabric to support the creation of wealth, employment and welfare. In this context, the aim of this research is to confirm a theoretical model based on Expectancy Theory to explain self-employment in terms of an individual's motivation and ability to start a business. Because of the lack of additional information about entrepreneurial motivation, we conducted a field investigation of Spanish self-employed workers who had established a manufacturing company during the last three years. The results confirm the supposition that expectancy, instrumentality and valence enhance entrepreneurial motivation. This study concludes that businesses are created not only by those with the ability and aptitude to do so, but also by those with the motivation.
\end{abstract}

Keywords Entrepreneurial motivation - Entrepreneurship · Expectancy theory - Selfemployment

\section{Introduction}

During the economic crisis, which peaked in 2013, unemployment rates rose more than at any other time in recent history. In this context and due to looser restrictions of regional economic development policies (Budd and Hirmis 2004; Scott and Storper 2007), to attract large, established companies, endogenous development through new business creation became imperative. The starting point for this new regional economic development policy is that all territorial space has certain resources (either financial,

Virginia Barba-Sánchez

Virginia.Barba@uclm.es

1 Department of Business Science, University of Castilla-La Mancha, ESII, Paseo de los Estudiantes, s/n, Albacete 02006, Spain 
human, institutional or cultural) that are susceptible to mobilization by local actors to create jobs and wealth (Barba-Sánchez and Molina 2014).

The nature of these resources makes local endogenous development difficult because for consolidation, it must meet conditions involving human resources, industries and existing services, financial availability and the existence of raw materials (Scott 1996). According to Isaksen (2001), these requirements highlight the need for a person to possess a certain business acumen, with not only the professional and business qualifications but also a favourable predisposition towards entrepreneurship (BarbaSánchez and Atienza-Sahuquillo 2012).

As Fernández-Serrano and Romero (2012) note, the phenomenon of entrepreneurship is of particular interest when governments realize that the state alone is unable to ensure adequate levels of production and employment, thereby resulting in high unemployment, and this explains why the topic of self-employment is so important for Europe. In the same vein, authors such as Feather (1992), Klyver et al. (2013) or Shapiro (2014) have found a certain relationship between the degree of unemployment and the growth rate of self-employment, which implies that the latter increases when salary-based employment opportunities are limited. In addition, Shapiro (2014) shows that economies with a greater share of self-employment exhibit faster economic recovery. This is why governments encourage new businesses since they are one of the cornerstones in any initiative geared towards employment generation, because of the need to act as a driving force for creativity and risk taking (Scott and Storper 2007). Self-employment, however, suffers from high levels of abandonment and this means that these policies do not obtain the desired results. While specialist literature (e.g. Uddin and Kanti 2013; Hopp and Sonderegger 2015) has focused on analysing the reasons for such entrepreneurial failure, it is important to examine what makes selfemployed individuals continue with their activity.

Authors such as Baron (2004) or Holland and Garrett (2015) indicate that this decision to continue is connected with the expectations and values that are intrinsic to an entrepreneur's cognitive process. According to Colombo and Grilli (2016), very little has been published about the entrepreneur's decision to continue or not during an industry-specific crisis.

Current research corroborates a theoretical model based on Expectancy Theory to explain the continuation of self-employment in terms of the entrepreneur's motivation and ability. ${ }^{1}$ Our research contributes to a better understanding of entrepreneurial decision-making in turbulent times from an original perspective; in particular, we analyse the cognitive process that sustains persistence in solo self-employment and the transitions from solo self-employment to employership using Expectancy Theory. In addition, this paper contributes to debate about the best way to formulate this theory by comparing the two published proposals in order to select the one that best matches the analysed context.

The paper is structured as follows: Section 2 reviews some of the major research into entrepreneurship and entrepreneurial motivation; Section 3 explores the method

\footnotetext{
${ }^{1}$ For this research, a self-employed person is defined as someone with a residual income from a business where they work full time and for which they hold the majority ownership stake. According to Dawson and Henley (2013), this definition allows us to exclude non-business owners, including freelancers and subcontractors, and other unspecified non-business-owning self-employed people.
} 
followed, describes the sample and data sources and outlines how to measure the variables used in the analysis; Sections 4 and 5 present and discuss the results obtained and the main conclusions; and finally, Section 6 describes the limitations and implications of this study for future research and policy makers.

\section{Conceptual framework}

Within the field of the study of entrepreneurship, motivation research analyses an individuals' motives for starting a business (content-based motivation theories), disregarding the necessary cognitive process to make such a decision (process-based motivation theories). Many motivation theories such as Expectancy Theory have attempted to explain an individual's work performance in general terms (e.g. Chiang and Jang 2008) but few studies have applied these theories to the employer and the act of entrepreneurship (e.g. Gatewood et al. 2002; Hsu et al. 2014). Research usually attempts to define an entrepreneur's psychological profile to differentiate them from others (e.g. Karimi et al. 2017; Uddin and Kanti 2013). Although these studies consider different variables in the demographic sample profile and are not, therefore, directly comparable to the current study, they do identify entrepreneurs as having the following characteristics: desire for independence, greater propensity for risk, high need for achievement and a preference for innovation.

Another extensive line of research investigates the impact of motives or reasons for starting companies on entrepreneurial success and this is measured in terms of business growth (e.g. Edelman et al. 2010). While Carsrud and Brännback (2011) confirmed the existence of a significant relationship between both variables, other studies differ as to the extent of this relationship.

Finally, other published approaches have inferred positive correlations between the entrepreneur's motivation in terms of their willingness to invest time, energy and money on their business plan and their behaviour on issues such as strategy or their willingness to grow with the business (e.g. Zanakis et al. 2012). Along this line of thought, a new theoretical model is being developed that addresses the process and variables that influence corporate behaviour (e.g. Shepherd et al. 2015) i.e. the entrepreneur's ability and motivation.

In this body of theory, we view the contribution of Expectancy Theory (also known as the Theory of Motivation or the Rational Intention Theory) as significant since rational prioritization influences the effect of individual intentions on the motivationdecision-action process (Holland 2011; Reinharth and Wahba 1975). Under this approach, people act more from anticipation than from deprivation, as put forward by the traditional theory that individuals have a natural tendency to meet their basic needs (Locke and Baum 2007).

Lawler and Suttle (1973) propose that people will decide to behave or act in a certain way because they are motivated to select a specific behaviour over another because of what they expect the result of that selected behaviour to be. In essence, the motivation for behaviour selection is determined by the desirability of the outcome. However, at the core of the theory is the cognitive process of how an individual processes the various motivational elements and this occurs before the ultimate choice is made. According to Hirschi and Fischer (2013), the outcome is not the sole determining 
factor in deciding on how to behave. Expectancy Theory concerns the cognitive processes regarding choice or choosing and explains the processes that an individual undergoes to make a choice. In a given situation, therefore, people combine their needs with their beliefs and expectations of the chances of success.

Accordingly, Vroom (1964) defines motivation as a product of an individual's expectancy that a certain effort will lead to the intended performance, the instrumentality of this performance in achieving a certain result and the desirability of this result for the individual, known as valence. Additionally, Graen's (1969) proposed Expectancy Theory extension is based on the distinction between first- and secondorder results. He calls the first order "work role" and defines it as a set of behavioural expectations deemed appropriate for the person performing certain activities. The second order is known as "work role outcome" and is the result of the work related to intrinsic and extrinsic rewards and punishments that the individual receives from playing a role.

While many studies have explored the empirical application of Expectancy Theory in the field of entrepreneurship (e.g. Gatewood et al. 2002; Edelman et al. 2010) not all have demonstrated the interrelationships proposed by Vroom (1964). They generally confirm the basic assumptions in a variety of real-life situations in the industry field (Renko et al. 2012). Locke and Baum (2007), for example, argued that Expectancy Theory provides an excellent framework for understanding why and how someone people choose to be entrepreneurs.

In their research, Hsu et al. (2014) examined university students enrolled on an introductory entrepreneurship course and found that "expectancy theory would predict that an individual will be motivated to invest the effort necessary to start a business if he/she believes that high input of effort will make it feasible for him/her to attain desirable goals through business ownership (e.g. make more money, be independent, gain high social status, etc.)" (p. 123). In the same way, authors such as Gatewood et al. (2002) or Manolova et al. (2012) conceptualize new venture creation as a process based on the effort-performance-outcome model of entrepreneurial expectancies, or in other words, that entrepreneurial motivation would depend on three elements: expectancy, instrumentality and valence. Accordingly, the following hypothesis is formulated:

Hypothesis 1: Self-employed expectancy, instrumentality and valence of business ownership will predict a person's motivation to remain self-employed.

Vroom (1964), however, distinguishes between first-order valence or work role and second-order valence and work role outcome. The difference lies in the fact that while the first refers to the desirability, for example, of being self-employed, the second refers to the desirability of the results obtained from being self-employed. In this respect, authors such as Manolova et al. (2012) or Renko et al. (2012) also distinguish between first-level and second-level outcomes in that the first are ends in themselves whereas second-level outcomes are instrumental in achieving other results. In short, as Lawler and Suttle (1973) argued, first-order valence depends on instrumentality and secondorder valence. The following hypothesis is therefore proposed:

Hypothesis 1a: A person's attraction to being self-employed (first-order valence) depends on their perception that doing so will lead to the production of other outcomes (instrumentality) and the desirability of the latter (second-order valence).

The motivational force (as defined in expectancy theory) is also the amount of effort a person will put into achieving a specific goal (Lawler and Suttle 1973). Holland 
(2011) examined entrepreneurs' motivation to persist with existing businesses and found that "when the outcome valences are high, the motivation to persist is likely to be high" (p.347). The following hypothesis is therefore proposed:

Hypothesis 1b: A person's motivation to remain self-employed (motivation) depends on the subjective likelihood of achieving it (expectancy) and the attractiveness of being self-employed (first-order valence).

Following Manolova et al. (2012), the predictive power of the expectancy model extends beyond entrepreneurial motivation since it supposes a decisionmaking process. Expectancy theory assumes that action (e.g. new venture formation) will be taken when an individual believes himself or herself to be sufficiently able or motivated for this action (Gatewood et al. 2002). Van Eerde and Thierry (1996) performed a meta-analysis of seventy-seven studies and concluded that expectancy theory significantly predicted performance, effort, intentions, preference and choice. More recently, Hsu et al. (2014) also indicated that enough empirical evidence exists of the positive correlation between an individual's level of execution/action and their motivation and ability. In short, people avoid activities that they believe exceed their abilities and choose those they feel they are capable of handling (Hopp and Sonderegger 2015).

Furthermore, as Holland and Garrett (2015) argued, persistence is vital to entrepreneurial success. Millán et al. (2012) examined the transition out of self-employment into other situations (paid employment, unemployment and inactivity) and assumed that "a rational individual will quit self-employment to enter paid-employment if the expected utility from self-employment is smaller than the expected utility from a wage employment offer received" (p. 85). However, Millán et al. (2014) obtain strong evidence to support the supposition that self-employers persist in running their businesses, although the extent of this persistence varies according to their previous situation and is lower if they were previously unemployed. These findings are consistent with the view that there are two rather different types of entrepreneurship: opportunity and necessity, as defended by the Global Entrepreneurship Monitor (see Reynolds et al. 2002). In this context, the following hypotheses are considered:

Hypothesis 2: Motivation (or the effort that the founder is willing to exert in order to remain self-employed) and ability (in terms of entrepreneurial experience and training) will influence a person's decision to remain self-employed in such a way that if either of the two variables is weak, the positive effect of the other variable will be reduced.

By way of summary, Fig. 1 shows the proposed research model for the working hypotheses. In line with the evidence offered by literature, we investigate the relationship between motivation and ability in terms of engaging in self-employment.

\section{Data and method}

\section{Data collection and sample}

Primary data was used to conduct this study. Because of the lack of any secondary information about self-employers' entrepreneurial motivation, we conducted field research into new Spanish entrepreneurs who had recently established manufacturing companies in Castilla-La Mancha during the past 


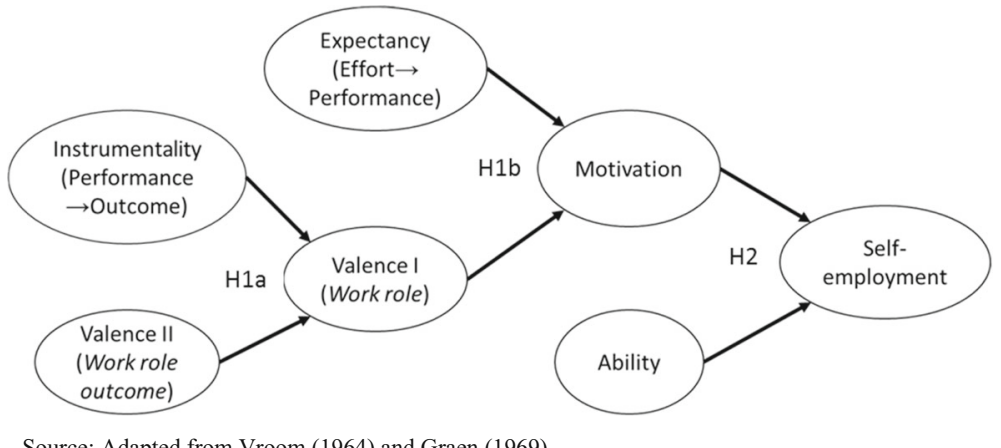

Source: Adapted from Vroom (1964) and Graen (1969).

Fig. 1 Research model and hypotheses

three years in order to exclude anyone who had retired. Research of this kind commonly focuses on recently established firms (e.g. Renko et al. 2012). We also focused on self-employers in manufacturing industries because of the differences in commitment between these new entrepreneurs and those from service industries (Townsend et al. 2010). Following Assael and Keon (1982), we used a proportionate sampling method to capture heterogeneity within the manufacturing companies.

Following a series of in-depth qualitative interviews, a survey was designed and sent to those who had been invited to take part. Follow-up requests went out several weeks after the initial mailing. Of the 2848 questionnaires mailed, 117 usable surveys were returned and 101 were properly completed. This is a representative sample of Spanish manufacturing companies located in Castilla-La Mancha (joint margin of error of $+/-$ $3.3 \%$ and a level of confidence of 95\%). We analysed collected data from 101 selfemployers using the multiple regression method in SPSS for Windows. More specifically, we used ordered logistic regression since the dependent variables of the model are categorical variables.

With regard to nonresponse bias, Rogelberg and Stanton (2007) presume that late respondents exhibit similar characteristics to nonrespondents. One way to assess nonresponse bias is to compare characteristics from early and late respondents. No significant differences emerged between late and early respondents for all four characteristics using single-tail $t$-tests at the .05 significance level.

The data show that Spanish entrepreneurs are overwhelmingly male (only $9 \%$ were women) with an average age of 40 years, although many started out in business at the age of 29. Fifty-four percent have family responsibilities (a person, spouse or children, etc. who are financially dependent on them) and most worked for someone else before starting their own business, having accumulated an average of 9.858 years of experience, usually in the same sector. In terms of education, most had finished secondary education and had the equivalent of a high school diploma or above, although $13 \%$ had finished neither primary nor secondary education. Such educational shortcomings were remedied, however, through further training on additional business creation (44\% of the sample). In addition, $83 \%$ of the entrepreneurs had partners (average of more than 2) and the main reasons for partnership were technical skills, entrepreneurial ability and sectorial experience. 


\section{Measures}

The measures reported here include expectancy, instrumentality, valence and entrepreneurial motivation and ability as independent variables. The decision to remain selfemployed is the dependent variable.

\section{Expectancy: effort $\rightarrow$ performance $(E \rightarrow P)$}

Expectancy is the belief that one's effort (E) will result in the attainment of desired performance (P) goals. As mentioned previously, Graen (1969) further distinguishes first-order results, which refer to the achievement of a certain behaviour or level of performance (in our case, the act of becoming selfemployed), from second-order results, or the rewards or penalties that the individual receives as a result of achieving a certain level of performance or simply for performing the activities relating to a certain task (in this case, selfemployment). In turn, these two levels can be divided into intrinsic and extrinsic: the first concerns the characteristics and content of the work itself and can be self-administered whereas the second results from the environment where the task is implemented and is externally managed. We adapted the items used to measure expectancy from Renko et al. (2012) and measured them on a five-point Likert scale ( 1 = "strongly disagree" or "belief they would be unable to perform successfully" to $5=$ "strongly agree" or "firm belief they could perform successfully").

\section{Instrumentality: performance $\rightarrow$ outcome $(P \rightarrow O)$}

Instrumentality is a person's belief that they will be rewarded for meeting performance expectations. This reward may come in the form of a pay increase, promotion, recognition or sense of accomplishment. Instrumentality is low when the reward is given for all levels of performance. Following Manolova et al. (2007) and Renko et al. (2012), we measured instrumentality using a single item on a five-point Likert scale ( $1=$ "strongly disagree" or "no relationship between performance and outcome" to $5=$ "strongly agree" or "outcome is entirely dependent on performance").

\section{Valence I and II}

The valence or orientation of a person to certain outcomes (Vroom 1964) is the subjective value of rewards a priori and expresses the force of an individual's attraction to a specific outcome. Graen (1969) further distinguishes between valence and value of an outcome and so the anticipated satisfaction associated with achieving an outcome (valence) differs from the real satisfaction (value) of an outcome.

We adapted items measuring valence from Graen (1969) and respondents evaluated the desirability of self-employment (first-order valence) and selfemployment work outcomes (second-order valence) using a five-point Likert scale $(1=$ "very undesirable" or "avoidance of outcome" to $5=$ "very desirable" or "expected outcome would be very satisfactory"). 


\section{Motivation force}

In the Expectancy Theory model, motivation is conceptualized as the degree of eagerness to achieve a goal and the probability that it can be achieved successfully and as desired. In this sense, according to Uy et al. (2015), motivation captures an individual's willingness to exert particular efforts towards their objective, while committing themselves for a particular time to working towards a predetermined objective. Respondents evaluated the entrepreneurial effort intensity, or how hard an entrepreneur works towards establishing a viable business venture, using a five-point Likert scale ( 1 = "very little effort" to $5=$ "a great deal of effort").

\section{Entrepreneurial ability}

Following Townsend et al. (2010), we measured the perception of selfconfidence in one's entrepreneurial ability using three items on a five-point Likert scale ( $1=$ "strongly disagree" to $5=$ "strongly agree"). Respondents were asked whether they "have the knowledge, skill and experience required to start and manage a new business" and two more questions about their entrepreneurial experience and training.

\section{Decision to remain self-employed}

In line with Douglas and Shepherd (2002), we asked respondents to rate the likelihood of them remaining self-employed. We measured the decision outcome on a five-point Likert scale (1= "not at all likely to continue with current business" to 5= "highly likely to continue with the current business").

\section{Method}

Following Norusis (2005), we performed an ordered logistic regression because the dependent variables are categorical variables for which order is an important factor (Likert 5 scale). These ordinal regression models are an extension of the binary logistic regression model where the dependent variable would take more than two possible values (polytomous models). The dependent variable also tends to follow an order of precedence between the different categories, but the real distance between them is unknown. The parametric model considered is a multiple regression method of the form Eq. (1):

$$
\mathrm{Y}_{\mathrm{i}}=\beta_{0}+\beta_{1} \mathrm{X}_{\mathrm{i} 1}+\ldots+\beta_{\mathrm{K}} \mathrm{X}_{\mathrm{iK}} ; \mathrm{i}=1, \ldots, \mathrm{n}
$$

where $\mathrm{Y}_{\mathrm{i}}$ is the dependent variable and $\mathrm{X}_{\mathrm{iK}}$ are the independent variables.

The original proposition of Expectancy Theory is used in a multiplicative approach when assessing motivational force (Vroom and Jago 1978). In this regard, for example, the influence of high levels of expectancy on motivation is more prominent when the value of the outcomes is perceived as high than 
when it is perceived as low. Thus, Vroom's Models (Vroom 1964) have the following specifications Eqs. (2 and 4):

$$
F=\sum_{j=1}^{n}\left(E_{i j} V_{j}\right)
$$

where $\mathrm{F}$ is the force to perform an act or motivation (job effort), $\mathrm{E}$ is the expectancy that an act will be followed by outcome $\mathrm{j}$ and $\mathrm{V}$ is the valence of outcome $\mathrm{j}$ or degree of satisfaction of outcome $\mathrm{j}$.

$$
\mathrm{V}_{\mathrm{j}}=\sum_{k=1}^{n}\left(I_{j k} V_{k}\right)
$$

where $\mathrm{V}$ is the valence of outcome $\mathrm{j}$ (job satisfaction), $\mathrm{I}$ is the instrumentality of outcome $\mathrm{j}$ for attainment of outcome $\mathrm{k}$ and $\mathrm{V}$ is the valence of outcome $\mathrm{k}$.

$$
P=F \times A=\sum_{j=1}^{n}\left(E_{i j} V_{j}\right) A
$$

where $\mathrm{P}$ is the job performance, $\mathrm{F}$ is the motivation to perform an act, $\mathrm{E}$ is the expectancy that act $i$ will be followed by outcome $j, V$ is the valence of outcome $j$ and $\mathrm{A}$ is the abilities to perform an act.

This multiplicative approach has been used by Fitzsimmons and Douglas (2011) and Holland (2011). However, authors such as Julian and Ofori-Dankwa (2008) or Renko et al. (2012) suggest that entrepreneurial studies should examine the independent effects of the causes. In particular, Renko et al. (2012) explain that entrepreneurs may doubt their skills and abilities (low expectancy levels) but still put a great deal of effort into starting their own business given the high valence they place on the financial rewards it could bring. Consequently, we applied two approaches to address research issues. Firstly, we tested the additive model hypothesis by assessing variables individually (see Eq. 5) and secondly, we adopted the multiplicative formula by assessing positive interactive effect (see Eq. 6).

$$
\begin{aligned}
& P=F+A=\sum_{j=1}^{n}\left(E_{i j}+V_{j}\right)+\mathrm{A}(\text { for additive model }) \\
& P=F \times A=\sum_{j=1}^{n}\left(E_{i j} V_{j}\right) \text { A }(\text { for multiplicative model })
\end{aligned}
$$

where $\mathrm{P}$ is the decision to remain self-employed, $\mathrm{F}$ is the motivation, $\mathrm{A}$ is the entrepreneurial capacity, $\mathrm{E}$ is the expectancy that being self-employed will be followed by outcome $\mathrm{j}$ and $\mathrm{V}$ is the desirability of outcome $\mathrm{j}$.

\section{Results}

We analysed the relationship between the decision to remain self-employed and motivation and entrepreneurial capacity in three stages. First, we analysed first-order valence in terms of instrumentality and second-order valence. Secondly, we identified motivation in terms of life expectancy and first-order valence. Thirdly, we assessed the decision to remain self-employed in terms of motivation and ability. 


\section{First-order valence according to instrumentality and second-order valence}

The dependent variable in determining first-order valence $(V A L 1 L)$ is the entrepreneur's desire to undertake a business project (i.e. the attraction to be the founder of a company). Instrumentality or the entrepreneur's belief in the second-order results that will follow business creation (INSTL) and the attractiveness of these results to the entrepreneur (VAL2L) are independent variables that explain first-order valence. It is worth mentioning that since Vroom's (1964) theoretical model has no constant, our approach does not have one either.

\section{Additive model}

We estimated the additive model and Table 1 shows the results of this estimation using the ordinary least squares model (OLS). The first rows display the results of various goodness-of-fit tests as a whole. In overall terms, the model is significant with an explanatory power of 95.051 per 100 of the variability of the dependent variable (VAL1L) without this structural problem, according to $F$-test and Durbin-Watson (DW) methods.

In individual terms, this additive model verifies the relationship between $V A L 1 L$ and INSTL, while VAL2L is incorporated into the explanation of the dependent variable with a positive but nonsignificant relationship. We cannot therefore affirm that the desire to start a business is influenced by the desire for personal gain or social power, economic security or professional success. However, our data confirm that it can be influenced by the entrepreneur's perceived probability of accomplishing these things. In this case, the additive model does not fit theoretical reasoning.

\section{Multiplicative model}

For the multiplicative model formulation, we use logarithms to convert the expression into a sum that can be estimated by least squares. The results are shown in Table 2 and these indicate that the model is significant, explaining 95.386 per 100 of the total variability of the dependent variable $\left(\mathrm{R}^{2}\right)$ without collinearity or autocorrelation issues, according to $F$-test and Durbin-Watson methods.

On an individual level, both parameters are also positive and the level of statistical significance associated with $T$ is 0 , which verifies the relationship between first-order valence (desire to embark on creating a business) and instrumentality (the

Table 1 Analysis of (INSTL, VAL2L) on (VAL1L) using additive model

Joint analysis

$\mathrm{R}^{2}=95,051 \% \quad \mathrm{R}_{\mathrm{a}}^{2}=94,950 \% \quad \mathrm{~F}=941,19 ; \quad$ Sig. $=.0000 \quad \mathrm{E}=1.01320 ; \quad \mathrm{DW}=1.73753$

Individual analysis

\begin{tabular}{llllll}
\hline Variables & $\mathrm{B}$ & $\Sigma(\beta)$ & $\mathrm{T}$ & Sig. T & Relationship \\
\hline INSTL & 1.055725 & .034228 & 30.844 & .0000 & Positive; significant \\
VAL2L & .008018 & .020226 & .396 & .6927 & Positive; not significant \\
\hline
\end{tabular}


Table 2 Analysis of (INSTL, VAL2L) on (VAL1L) using multiplicative model

Joint analysis

$R^{2}=95.386 \% \quad R_{\mathrm{a}}^{2}=95.292 \% ; \quad F=1012.98 ; \quad$ Sig. $=.0000 \quad e=.14008 ; \quad D W=1.82358$

Individual analysis

\begin{tabular}{llllll}
\hline Variables & $\beta$ & $\sigma(\beta)$ & $\mathrm{T}$ & Sig. T & Relationship \\
\hline Log INSTL & .681740 & .095230 & 7.159 & .0000 & Positive; significant \\
Log VAL2L & .348028 & .088671 & 3.925 & .0002 & Positive; significant \\
\hline
\end{tabular}

entrepreneur's perception of the likelihood that creating a business will produce professional success, financial security, etc.) and second-order valence (desire to obtain professional success, financial security, etc.). However, the contribution of these variables to the model is not homogeneous. We observed that the ratio of the first $(\beta 1)$ is significantly higher than the second ( $\beta 2)$, which indicates that the former has a greater influence on estimating the value of the dependent variable than the latter.

\section{Comparison of additive and multiplicative models}

When compared with the additive model, the multiplicative model presents a better match to the theoretical framework in explaining the prevalence of first-order valence as a function of both the instrumentality and second-order valence. The multiplicative model also achieves the following:

- It increases the percentage of variability of the values of the dependent variable explained by the independent variables by .335 per $100\left(\mathrm{R}^{2}\right)$.

- It improves the outcome of the $F$-test, which indicates that the multiplicative model's prediction by the sample mean is better than the additive model's prediction.

- It significantly reduces the standard error of the estimate (e) from 1.01320 in the additive model to .14008 in the multiplicative model.

- In both cases, the Durbin-Watson test result is close to 2 but the multiplicative model is slightly closer to this value, which verifies the uncorrelated residues and the independence of the sample observations.

Consequently, the multiplicative model is a better measure of the theoretical framework.

\section{Role of motivation in expectation and first-order valence}

We then analyse the data using the entrepreneur's motivation to start a new business (MOTL) and this is understood in the broadest sense as the effort the entrepreneur is willing to exert (i.e. time, energy and money) as the dependent variable. The expectation of whether a project will be completed (EXPL) and the appeal to the entrepreneur $(V A L 1 L)$ are independent variables. In order to establish whether such a relationship exists, we performed a regression from Vroom's (1964) formulation. Although Vroom 
proposes a multiplicative model, other studies such as those by Arvey and Dunnett (1970) or Chiang and Jang (2008) also consider the additive model to be feasible and so we performed both and then compared the advantages of each.

\section{Additive model}

Table 3 shows the results of the OLS estimation. The first rows display the results of various tests that confirm goodness of fit as a whole. The data therefore confirm that the additive model is significant, explaining 97.864 per 100 of variability of the dependent variable $(M O T L)$ without problems of collinearity or autocorrelation, according to $F$ test and the Durbin-Watson test, respectively.

The second part of the table shows the results in individual terms, with the independent variables in the left column followed by parameter estimates for the model tested and the $T$-test result for each, with the degree of significance attached. We observe that this additive model verifies the relationship between an entrepreneur's motivation to start a business and their desire to create a company in that the regression coefficients for both are positive; the larger one variable is, the greater the other one will be. However, the contribution of these variables to the model is not homogeneous. We observe that the ratio of the first $(\beta 1)$ is significantly higher than that of the second $(\beta 2)$, which indicates that the former has a greater influence on estimating the value of the dependent variable than the latter.

This finding does not necessarily mean that their contribution is representative. Using $T$-tests to contrast the null hypothesis for each of the independent variables, we determined that this variable does not improve the prediction of the dependent variable on the regression obtained with the other independent variable. The results provide a level of significance associated with $T$ equal to 0 , thus rejecting the null hypothesis, which indicates that the contribution of either independent variable is significantly different from 0. Consequently, we conclude that the motivation to start a business can be explained from the entrepreneur's expectation (or perception of the likelihood) of success and the attraction of creating a business.

\section{Multiplicative model}

On the other hand, the multiplicative model uses logarithms to convert the expression into a sum that can be estimated by least squares. The results are shown in Table 4 and

Table 3 Analysis of (EXPL, VAL1L) on (MOTL) using additive model

Joint analysis

$R^{2}=97.864 \% ; \quad R_{\mathrm{a}}^{2}=97.82 \% ; \quad F=2245.16 ; \quad$ Sig. $=.0000 ; \quad e=.68834 ; \quad D W=1.38505$

Individual analysis

\begin{tabular}{llllll}
\hline Variables & $\beta$ & $\sigma(\beta)$ & $T$ & Sig. $T$ & Relationship \\
\hline EXPL & .533703 & .078450 & 6.803 & .0000 & Positive; significant \\
VAL1L & .485318 & .079732 & 6.087 & .0000 & Positive; significant.
\end{tabular}


Table 4 Analysis of (EXPL, VAL1L) on (MOTL) using multiplicative model

Joint analysis

\begin{tabular}{llllll}
\hline $\begin{array}{l}R^{2}=98.608 \% \\
\text { Individual analysis }\end{array} R_{\mathrm{a}}^{2}=98.58 \% ;$ & $F=3471.13 ;$ & Sig. $=.0000$ & $e=.07906 ;$ & $D W=1.35454$ \\
\hline Variables & $\beta$ & $\sigma(\beta)$ & $T$ & Sig. $T$ & Relationship \\
\hline $\log$ EXPL & .709050 & .061203 & 1.585 & .0000 & Positive; significant \\
$\log$ VAL1L & .304350 & .062161 & .896 & .0000 & Positive; significant \\
\hline
\end{tabular}

these indicate that the whole model is significant, explaining 98.608 per 100 units of the total variability of the dependent variable, without presenting problems of collinearity or autocorrelation, according to the $F$-test and Durbin-Watson test, respectively.

On an individual level, the parameters are also positive and significant, which further confirms that the dependent variable can be explained in terms of a direct relationship. There is a buffering effect or accelerator, according to the respective values of the independent variables, i.e. an expectation of the valence and vice versa in relation to the combined effect of both variables on motivation to start a business.

Regarding the contribution of each independent variable (EXPL), both have a major impact on estimating the value of the dependent variable and both are representative (significant $T$ level equals 0 ).

\section{Comparison of both models}

When comparing both formulations, we observed the following differences in terms of the parameter values and goodness of fit:

- The multiplicative model showed slight improvement over the additive model in the explanatory model, as the $\mathrm{R}^{2}$ increased by .744 per 100 .

- The multiplicative model showed a significant improvement over the additive model with respect to the $F$-score, which indicates that the multiplicative model's prediction by the sample mean is better than the additive model's.

- The multiplicative model showed significant improvement over the additive model with regard to the standard error of the estimate (e), which decreases from .68834 to .07906.

- We observed a slightly higher value for the multiplicative over the additive model in the Durbin-Watson analysis, although in both cases the value is close to 2 , confirming the uncorrelated residues and independence of the sample.

- In the multiplicative model, we noted a greater difference between the values of the parameters of the independent variables, which influences their contribution to the explanation of the dependent variable.

Consequently, although the additive model is also valid from the standpoint of the literature, we chose the multiplicative model because this model produced the best results in various statistical tests. 


\section{The decision to remain self-employed as a function of motivation and ability}

We next analysed the data using the decision to remain self-employed (SEMPL) as the dependent variable. We do not intend to measure entrepreneurial intention, which would require using a prospective approach (Manolova et al. 2007; Douglas 2013), but rather to determine whether the decision to create a company was successful. We decided to use this post or retrospective approach because we want to know which variables explain the triggering behaviour when the potential entrepreneur ultimately decides to carry out the business plan and succeeds in this undertaking, defined in this study as not regretting their actions. In this regard, the potential drawbacks underscored by Mattheus and Moser (1996) had no effect. The motivation to start a new business or level of effort the entrepreneur is willing to exert to create the company (MOTL) and the aptitude, or ability, knowledge and experience of the self-employer $(A B I L)$ are the independent variables.

\section{Additive model}

Table 5 presents the results of the analysis using OLS. The first rows display various tests confirming the goodness of fit as a whole. We therefore conclude that the additive model is significant, explaining 83.804 per 100 of the variability of the dependent variable (SEMPL's) without presenting problems of collinearity or autocorrelation, according to the $F$-test and Durbin-Watson test, respectively.

On an individual level, the additive model verifies the relationship between the decision to remain self-employed (SEMPL) and the motivation to start a new business $(M O T L)$ because the direction is positive and the relationship is significant. This is not the case for the entrepreneur's ability $(A B I L)$ where the relationship has a positive direction but is not significant. In this regard, the data do not support the fact that the decision to create a company is influenced by the entrepreneur's knowledge and skills and the theoretical framework cannot therefore be validated through this model.

\section{Multiplicative model}

The multiplicative model uses logarithms to convert the expression into a sum that can be estimated by least squares. The results are shown in Table 6 and these indicate that the model is significant, explaining 92.586 per 100 of the total variability of the dependent variable with no problems of collinearity or autocorrelation, according to

Table 5 Analysis of (MOTL, ABIL) on (SEMPL) using additive model

Joint analysis

$R^{2}=83.804 \% ; \quad R_{\mathrm{a}}^{2}=83.474 \% ; \quad F=253.55 ; \quad$ Sig. $=.0000 \quad e=1.68058 ; \quad D W=2.08947$

Individual analysis

\begin{tabular}{llllll}
\hline Variables & $\beta$ & $\sigma(\beta)$ & $T$ & Sig. $T$ & Relationship \\
\hline MOTL & .557395 & .145586 & 3.829 & .0002 & Positive; significant \\
ABIL & .297404 & .166659 & 1.785 & .0774 & Positive; not significant \\
\hline
\end{tabular}


Table 6 Analysis of (MOTL, ABIL) on (SEMPL) using multiplicative model

Joint analysis

$R^{2}=92.586 \% ; \quad \mathrm{R}_{\mathrm{a}}^{2}=92.418 \% ; \quad F=549.50 ; \quad$ Sig. $=.0000 \quad e=.17147 ; \quad D W=2.03291$

Individual analysis

\begin{tabular}{llllll}
\hline Variables & $\beta$ & $\sigma(\beta)$ & $T$ & Sig. $T$ & Relationship \\
\hline Log MOTL & .534920 & .131321 & 4.073 & .0001 & Positive; significant. \\
Log ABIL & .416334 & .146583 & 2.840 & .0056 & Positive; significant. \\
\hline
\end{tabular}

the $F$-statistic and Durbin-Watson test, respectively. On an individual level, the parameters are also positive and significant.

In separately analysing each of the independent variables (individual analysis in Table 6), it is evident that even though the contribution of both is significant, the motivation to start a new business influences the entrepreneur's ability to achieve their goals to a greater extent.

\section{Model comparison}

When compared with the additive formulation, the multiplicative one presents a better match to the theoretical framework in explaining the decision to create a business in terms of both motivation to start such a project and the entrepreneur's ability, indicating the significant contribution of both variables. It also features the following goodness-of-fit observations:

- Improved explanatory power regarding the variability of the dependent variable, as the $\mathrm{R}^{2}$ increased by 8.782 per 100 .

- Superior value in the $F$-statistic, which indicates that the multiplicative model's prediction by the sample mean is better than the additive model's.

- Lower error of the multiplicative model's estimate $(e=.17147)$ than the additive model's $(e=1.68058)$, meaning that the difference between the observed and estimated standard error is smaller.

- Slightly higher Durbin-Watson statistic value in the multiplicative model than in the additive model, though in both cases the value is close to 2, confirming the uncorrelated residues and independence of sample observations.

In summary, Fig. 2 shows the results of the final model. We chose the multiplicative model for the formulations since this model obtained better results than the additive model.

\section{Conclusions}

In order to examine how motivation and entrepreneurial skills affected the decision to remain self-employed from the perspective of the Expectancy Theory of Motivation, we established a series of working hypotheses on the mechanisms that trigger human actions or behaviour and from these we were able to reach the following conclusions: 


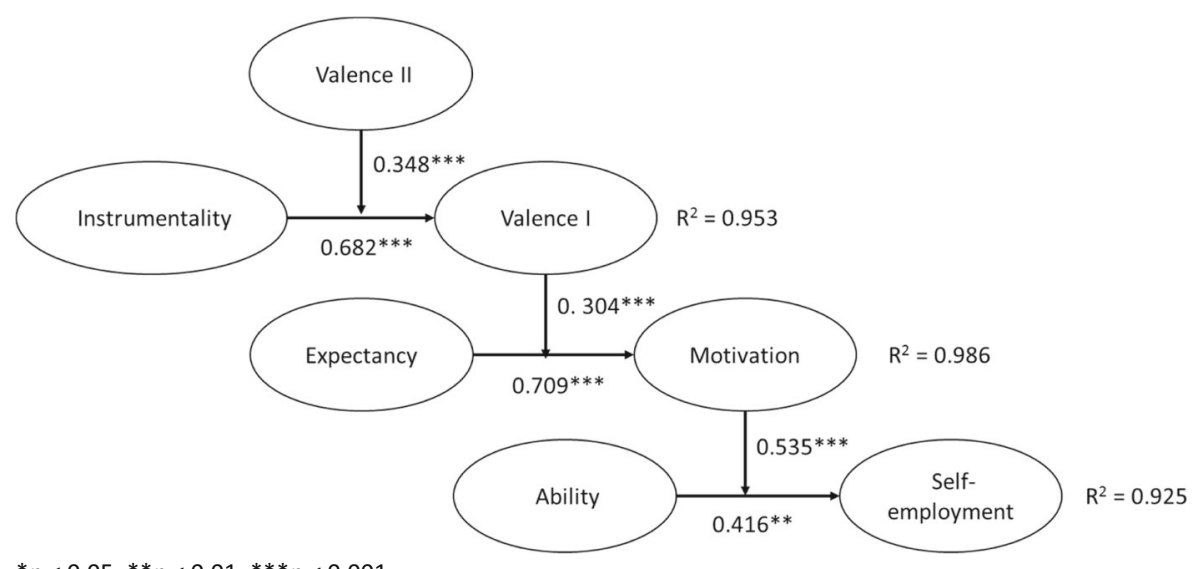

${ }^{*} p<0.05 ;{ }^{* *} p<0.01 ; * * * p<0.001$

Fig. 2 Final model's results

- Motivation (i.e. the effort that someone is willing to make to start up their own business) and abilities in terms of experience and training are determining factors in the decision to remain self-employed, in support of Hypothesis 1.

- A person's motivation to become self-employed is based on the subjective probability that their efforts will be followed by a specific outcome and the attractiveness of that outcome, in support of Hypothesis 2.

- The attraction of being self-employed for a given person depends on their perception that it will lead to desirable outcomes, in support of Hypothesis 3.

Finally, by testing these hypotheses we were able to answer the main research question affirmatively to prove that an individual's entrepreneurial motivation is indeed important in the decision to remain self-employed.

The results obtained are consistent with the empirical evidence offered by Gatewood et al. (2002), Bayon et al. (2015) and Uy et al. (2015) regarding the critical importance of motivation as a driving force for business creation and also commitment and aptitude. Correspondingly, according to Holland and Garrett (2015), businesses are not only created by those who have the ability and aptitude to do so but also by those with the motivation. Both variables are important for self-employed persistence and have interesting practical implications.

Practical implications for entrepreneurial education are also provided by better insights into the cognitive self-employed process. Since motivation is very important in promoting entrepreneurship and its persistence according to the conclusions of Barba-Sánchez and Atienza-Sahuquillo (2016) or Entrialgo and Iglesias (2016), schools and universities play an important role in encouraging and motivating students in the development of their entrepreneurial career.

Government agencies, venture capital companies, banks and others should also take this significant observation into account to measure the potential entrepreneur's commitment in order to reduce the high failure rate and better manage subsidies and funds for small enterprises and the self-employed. This should be borne in mind when designing programs to promote entrepreneurship since it is harder to remain selfemployed than it is to start being so, as Holland and Garrett (2015) highlighted. 


\section{Limitations and future research}

This study is subject to various limitations. Firstly, one empirical limitation is our use of single-item measures for all variables of the proposal model. According to Miller et al. (2009), the measuring instrument should include multiple items to assess similar content for developing a scale with adequate psychometric properties. This gap should be addressed in future studies. For example, the entrepreneurial intention measure could be improved by adding more items using Liñán and Chen's (2009) six-item scale and this would enable the researcher to value the entire dimension of this entrepreneurial intention.

A second limitation of the study is the relatively small sample size and the use of participants in only one region of Spain, which limits generalization of the findings (Santos-Álvarez and García-Merino 2016). Future research should use new, larger and more diverse samples. We therefore call for further primary studies to contribute to these research areas so that more accurate conclusions can be drawn.

Thirdly, our study only considered the entrepreneur's perspective. Future research could go beyond the individual by considering an entrepreneurial team perspective (Drnovsek et al. 2009) and including other concepts which are relevant to entrepreneurial motivation, such as entrepreneurial passion (Murnieks et al. 2014) or entrepreneurial optimism (Hmieleski and Baron 2009). The model presented and tested in this paper should be extended to incorporate other aspects of the decision to remain self-employed so that it can predict and explain an individual's decision to remain self-employed or become a salaried worker.

Future research could also take into account other moderating factors that may influence attitudes towards the enterprise, such as gender, ethnic background and a family background of business ownership. For policy makers, the findings provide evidence for the efficacy of different types of public subsidy programmes for different target groups, thus helping to identify how best to target resources and investment. In summary, this research has important implications for nations, entrepreneurs, investors and educators, but further research remains to be conducted.

Acknowledgements We acknowledge the financial support of European Regional Development Fund (ERDF) and University of Castilla-La Mancha (GI20142978). Thanks to Dr. Rodrigo Lozano for helpful and constructive comments on an earlier draft. Finally, we are grateful for the constructive remarks provided by the Editor and two anonymous reviewers.

Open Access This article is distributed under the terms of the Creative Commons Attribution 4.0 International License (http://creativecommons.org/licenses/by/4.0/), which permits unrestricted use, distribution, and reproduction in any medium, provided you give appropriate credit to the original author(s) and the source, provide a link to the Creative Commons license, and indicate if changes were made.

\section{References}

Arvey, R. D., \& Dunnett, M. D. (1970). Task performance as a function of perceived effort-performance and performance-reward contingencies. Minneapolis, Minn: University of Minnesota, Technical Report Center or the Study of Organizational Performance and Human Effectiveness. Retrieved from http://files.eric.ed.gov/fulltext/ED085636.pdf

Assael, H., \& Keon, J. (1982). Nonsampling vs. Sampling Errors in Survey Research. Journal of Marketing, 46, 114-123.

Barba-Sánchez, V., \& Atienza-Sahuquillo, C. (2012). Entrepreneurial behavior: Impact of motivation factors on decision to create a new venture. European Research on Management and Business Economics, 18(1), 132-138. 
Barba-Sánchez, V., \& Atienza-Sahuquillo, C. (2016). The development of entrepreneurship at school: The Spanish experience. Education + Training, 58(7-8), 783-796.

Barba-Sánchez, V., \& Molina, E. (2014). Entrepreneurship as a survival-seeking strategy for indigenous communities. In K. Todorov \& R. Smallbone (Eds.), Strategic management in small and medium enterprises: Theory and practice (pp. 398-420). Hershey, PA: IGI Global Business Science Reference.

Baron, R. A. (2004). The cognitive perspective: A valuable tool for answering entrepreneurship's basic "why" questions. Journal of Business Venturing, 19(2), 221-239.

Bayon, M., Vaillant, Y., \& Lafuente, E. (2015). Initiating nascent entrepreneurial activities: The relative role of perceived and actual entrepreneurial ability. International Journal of Entrepreneurial Behavior \& Research, 21(1), 27-49.

Budd, L., \& Hirmis, A. K. (2004). Conceptual framework for regional competitiveness. Regional Studies, 38, 1007-1020.

Carsrud, A., \& Brännback, M. (2011). Entrepreneurial motivations: What do we still need to know? Journal of Small Business Management, 49(1), 9-26.

Chiang, C. F., \& Jang, S. C. (2008). An expectancy theory model for hotel employee motivation. International Journal of Hospitality Management, 27, 313-322.

Colombo, S., \& Grilli, L. (2016). Should I stay or should I go? Founder's decision to leave an entrepreneurial venture during an industrial crisis. Industry and Innovation, published online. doi:10.1080 /13662716.2016.1216395.

Dawson, C., \& Henley, A. (2013). Over-optimism and entry and exit from self-employment. International Small Business Journal, 31(8), 938-954.

Douglas, E. J. (2013). Reconstructing entrepreneurial intentions to identify predisposition for growth. Journal of Business Venturing, 28(5), 633-651.

Douglas, E. J., \& Shepherd, D. A. (2002). Self-employment as a career choice: Attitudes, entrepreneurial intentions and utility maximization. Entrepreneurship Theory and Practice, 26(3), 81-90.

Drnovsek, M., Cardon, M. S., \& Murnieks, C. Y. (2009). Collective passion in entrepreneurial teams. In A. L. Carsrud \& M. Braanback (Eds.), Understanding the entrepreneurial mind (pp. 191-215). New York: Springer.

Edelman, L. F., Brush, C. G., Manolova, T. S., \& Greene, P. G. (2010). Start-up motivations and growth intentions of minority nascent entrepreneurs. Journal of Small Business Management, 48(2), 174-196.

Entrialgo, M., \& Iglesias, V. (2016). The moderating role of entrepreneurship education on the antecedents of entrepreneurial intention. International Entrepreneurship and Management Journal, 12(4), 1209-1232.

Feather, N. T. (1992). Expectancy-value theory and unemployment effects. Journal of Occupational \& Organizational Psychology, 65, 315-330.

Fernández-Serrano, J., \& Romero, I. (2012). Entrepreneurial quality and regional development: Characterizing SME sectors in low income areas. Papers in Regional Science, 92(3), 465-513.

Fitzsimmons, J. R., \& Douglas, E. J. (2011). Interaction between feasibility and desirability in the formation of entrepreneurial intentions. Journal of Business Venturing, 26(4), 431-440.

Gatewood, E. J., Shaver, K. G., Powers, J. B., \& Garner, W. B. (2002). Entrepreneurial expectancy, task effort and performance. Entrepreneurship Theory and Practice, 27(2), 187-206.

Graen, G. (1969). Instrumentality theory of work motivation: Some experimental results and suggested modifications. Journal of Applied Psychology, 53(2), 1-25.

Hirschi, A., \& Fischer, S. (2013). Work values as predictors of entrepreneurial career intentions. Career Development International, 18(3), 216-231.

Hmieleski, K. M., \& Baron, R. A. (2009). Entrepreneurs' optimism and new venture performance: A social cognitive perspective. Academy of Management Journal, 52, 473-488.

Holland, D. V. (2011). Utility maximization? An expectancy view of entrepreneurial persistence. Management Research Review, 34(3), 337-352.

Holland, D. V., \& Garrett, R. (2015). Entrepreneurs' start-up versus persistence decisions: A critical evaluation of expectancy and value. International Small Business Journal, 33(2), 194-215.

Hopp, C., \& Sonderegger, R. (2015). Understanding the dynamics of nascent entrepreneurship - Prestart-up experience, intentions and entrepreneurial success. Journal of Small Business Management, 53(4), 1076-1096.

Hsu, D. K., Shinnar, R. S., \& Powell, B. C. (2014). Expectancy theory and entrepreneurial motivation: A longitudinal examination of the role of entrepreneurship education. Journal of Business and Entrepreneurship, 26(1), 121-140.

Isaksen, A. (2001). Building regional innovation systems: Is endogenous industrial development possible in the global economy? Canadian Journal of Regional Science, 24(1), 101-120.

Julian, S. D., \& Ofori-Dankwa, J. C. (2008). Toward an integrative cartography of two strategic issue diagnosis frameworks. Strategic Management Journal, 29(1), 93-114.

Karimi, S., Biemans, H. J. A., Mahdei, K. N., Lans, T., Chizari, M. \& Mulder, M. (2017). Testing the relationship between personality characteristics, contextual factors and entrepreneurial intentions in a 
developing country. International Journal of Psychology, 52 (in press). Retrieved from http://onlinelibrary.wiley.com/doi/10.1002/ijop.12209/pdf

Klyver, K., Nielsen, S. L., \& Evald, M. R. (2013). Women's self-employment: An act of institutional (dis)integration? A multilevel, cross-country study. Journal of Business Venturing, 28(4), 474- 488.

Lawler, E. E., \& Suttle, J. L. (1973). Expectancy theory and job behavior. Organizational Behavior and Human Performance, 9, 482-503.

Liñán, F., \& Chen, Y. W. (2009). Development and cross-cultural application of a specific instrument to measure entrepreneurial intentions. Entrepreneurship Theory and Practice, 33(3), 593-617.

Locke, E. A., \& Baum, J. R. (2007). Entrepreneurial motivation. In J. R. Baum, M. Frese, \& R. A. Baron (Eds.), The psychology of entrepreneurship. SIOP organizational Frontiers series (pp. 93-112). Mahwah, NJ: Erlbaum.

Manolova, T. S., Brush, C. G., \& Edelman, L. F. (2007). What do women (and men) want? Entrepreneurial expectancies of women and men nascent entrepreneurs. Frontiers of Entrepreneurship Research, 27(8), Article 2.

Manolova, T. S., Brush, C. G., Edelman, L. F., \& Shaver, K. G. (2012). One size does not fit all: Entrepreneurial expectancies and growth intentions of US women and men nascent entrepreneurs. Entrepreneurship \& Regional Development, 24(1-2), 7-27.

Mattheus, C. H., \& Moser, S. B. (1996). A longitudinal investigation of the impact of family background and gender on interest in small firms ownership. Journal of Small Business Management, 34(2), 29-43.

Millán, J. M., Congregado, E., \& Román, C. (2012). Determinants of self-employment survival in Europe. Small Business Economics, 38(2), 231-258.

Millán, J. M., Congregado, E., \& Román, C. (2014). Persistence in entrepreneurship and its implications for the European entrepreneurial promotion policy. Journal of Policy Modeling, 36(1), 83-106.

Miller, V. A., Reynolds, W. W., Ittenbach, R. F., Luce, M. F., Beauchamp, T. L., \& Nelson, R. M. (2009). Challenges in measuring a new construct: Perception of voluntariness for research and treatment decision making. Journal of Empirical Research on Human Research Ethics, 4(3), 21-31.

Murnieks, C. Y., Mosakowski, E., \& Cardon, M. S. (2014). Pathways of passion: Identity centrality, passion and behavior among entrepreneurs. Journal of Management, 40(6), 1583-1606.

Norusis, M. (2005). Ordinal regression. In M. Norusis. SPSS 13.0 advanced statistical procedures companion (pp. 69-89). Upper Saddle River: Prentice Hall.

Reinharth, L., \& Wahba, M. A. (1975). Expectancy theory as a predictor of work motivation, effort, expenditure and job performance. Academy of Management Journal, 18(3), 520-537.

Renko, M., Kroeck, K. G., \& Bullough, A. (2012). Expectancy theory and nascent entrepreneurship. Small Business Economics, 39(3), 667-684.

Reynolds, P., Camp, S. M., Bygrave, W. D., Autio, E., \& Hay, M. (2002). Global entrepreneurship monitor 2001 executive report. Babson Park/London: Babson College and London Business School.

Rogelberg, S. G., \& Stanton, J. M. (2007). Understanding and dealing with organizational survey nonresponse. Organizational Research Methods, 10, 195-209.

Santos-Álvarez, V., \& García-Merino, T. (2016). Entrepreneurial motivation and informational attention in internationalization. Regional study to Spanish natural stone industry. European Research on Management and Business Economics, 22(1), 1-7.

Scott, A. J. (1996). Regional motors of the global economy. Futures, 28, 391-411.

Scott, A. J., \& Storper, M. (2007). Regions, globalization, development. Regional Studies, 41(Supplement 1), S191-S205.

Shapiro, A. F. (2014). Self-employment and business cycle persistence: Does the composition of employment matter for economic recoveries? Journal of Economic Dynamics and Control, 46, 200-218.

Shepherd, D. A., Williams, T. A., \& Patzelt, H. (2015). Thinking about entrepreneurial decision making: Review and research agenda. Journal of Management, 41(1), 11-46.

Townsend, D. M., Busenitz, L. W., \& Arthurs, J. D. (2010). To start or not to start: Outcome and ability expectations in the decision to start a new venture. Journal of Business Venturing, 25(2), 192-202.

Uddin, R., \& Kanti, T. (2013). Motivation, success factors and challenges of entrepreneurs in Khulna City of Bangladesh. European Journal of Business and Management, 5(16), 148-157.

Uy, M. A., Foo, M. D., \& Ilies, R. (2015). Perceived progress variability and entrepreneurial effort intensity: The moderating role of venture commitment. Journal of Business Venturing, 30(3), 375-389.

Van Eerde, W., \& Thierry, H. (1996). Vroom's expectancy models and work-related criteria: A meta-analysis. Journal of Applied Psychology, 81(5), 575-586.

Vroom, V. H. (1964). Work and motivation. New York: Wiley.

Vroom, V. H., \& Jago, A. G. (1978). On the validity of the vroom-Yetton model. Journal of Applied Psychology, 63, 151-162.

Zanakis, S. H., Renko, M., \& Bullough, A. (2012). Nascent entrepreneurs and the transition to entrepreneurship: Why do people start new businesses? Journal of Developmental Entrepreneurship, 17(1), 1-25. 